\title{
Sub-Chronic Effects of Gibberellic Acid Repeated Exposure on the Testis of Adult Albino Rats (Biochemical, Histopathological and Immunohistochemical Study)
}

\author{
Fatma Y. Farahat, Nermien A. Ibrahim, Sherien A. Elkhateeb', and Azza S. \\ Shehata $^{2}$
}

\footnotetext{
${ }^{1}$ Departments of Forensic Medicine \& Clinical Toxicology

${ }^{2}$ Departments of Histology and Cell Biology
}

Faculty of Medicine, Zagazig University, Zagazig, Egypt.

\begin{abstract}
Objective: Gibberellic acid (GA3) is a plant growth regulator (PGR), largely used in agriculture in many countries including Egypt. The purpose of this study was to investigate the effects of sub-chronic toxicity ( 8 weeks) of GA3 on testicular function and structure in adult albino rats, and to determine the effects of withholding of GA3 on the affected parameters for another 8 weeks of follow up period. Material and Methods: Forty adult male albino rats were equally divided into four groups; the first group was used as a negative control, the second group received $1 \mathrm{ml}$ of $1 \mathrm{~N} \mathrm{NaOH}$ (positive control group), the third group received 75 ppm of GA3 daily in drinking water for 8 weeks (GA3 group), and the last group received the same treatment as the third group for 8 weeks then was left without any treatment for another 8 weeks (recovery group). At the end of the experimental period, rats were sacrificed and the testes were examined by light and transmission electron microscope for detecting the histopathological changes, examination of sperm viability \& count and measuring testicular malondialdhyde. Testicular sections were examined immunohistochemically for the detection of the anti-apoptotic Bcl-2 protein. Results: In GA3 treated group, histopathological changes were in the form of regression in spermatogenesis using light microscope, while electron microscopic examination revealed apoptotic changes in the Leydig cells and distortion of the adluminal compartment. These changes were accompanied by significant elevation in testicular malondialdehyde, while Bcl-2 showed week immunoreactions in the layers of spermatids. After the 8 weeks of GA3 withholding, significant improvement in the testicular function and structure with improvement of Bcl-2 immunoreaction. Conclusion: From the previous results, it can be concluded that GA3 exposure can induce reversible toxic changes in the testes of adult albino rats on sub-chronic exposures.
\end{abstract}

Keywords Gibberellic acid, Testis, spermatogenesis, Bcl-2, Rats

\section{Introduction}

$\mathrm{M}$ any chemicals are currently used in agriculture, and plant growth regulators (PGRs) are among those which are widely used. The amounts of these substances placed into the environment may soon exceed those of insecticides (Celik and Tuluce, 2006).

Among PGRs, gibberellinA3 (GA3) was the one used in many countries including Egypt and Tunisia to increase the growth of fruits and vegetables (Troudi et al., 2010). Gibberellins (a group belonging to PGR) are plant hormones that regulate growth and influence various developmental processes, including stem elongation, germination, dormancy, flowering, sex expression, enzyme induction, and leaf \& fruit senescence (Fishel, 2006). They were discovered in 1926 by a Japanese scientist, Eiichi Kurosawa, who was studying bakanae, the "foolish seedling" disease in rice. It was first isolated in 1935 by Teijiro Yabuta from fungal strains of Gibberella fujikuroi (Drira, 2006).

Gibberellic acid (GA3) is one of the most active hormones of gibberellins, which is highly 
persistent and bioactive in soil for months, and the Environmental Protection Agency has determined its use to be only allowed in low doses (Schwechheimer \& Willige, 2009). Since animals and humans consume GA3 in their diet, it was hypothesized that metabolic events in their cells could influence such dietary ingredients (Srikumar et al. 2009). Therefore, GA3 could pose a risk to those exposed to it because of their profession, as well as the general population, by the excessive consumption of such food products (Hassan et al. 2013).

Previous studies indicated that GA3 alters the antioxidative systems in the rat's tissues. Antioxidant enzyme activities were significantly decreased in the liver, brain (Tuluce and Celik, 2006), and erythrocytes (Troudi et al., 2011) of rats treated with GA3. The lipid peroxidation end product malondialdehyde (MDA) significantly increased in the liver, lungs, heart and kidneys of rats treated with GA3 (Celik et al., 2007), where these findings indicated promotion of lipid peroxidation content and alteration in the antioxidant systems in the rat's various tissues treated with GA3.

In spite of the increasing use of this substance in agriculture, few researches have been done to study the toxic effect of GA3 on the male reproductive system. So, the present work aims to evaluate the possible adverse effects of GA3 on the testis of adult male albino rats for 8 weeks, and also to determine whether these effects are reversible or not after withholding GA3 administration for another 8 weeks of follow up period.

\section{Material and Methods}

\section{A- Material}

\section{1- Chemicals}

- Gibberellic Acid (2,4a, 7-Trihydroxy-1-methyl-8methylenegibb-3-ene-1, 10 - dicarboxylic acid1,4a-lactone) in the form of white crystalline powder, was from Sigma-Aldrich chemical Co., Germany.

- Sodium hydroxide: It was used to dissolve gibberellic acid. It was obtained from El- Nasr Co., Egypt.

\section{2- Kits}

Bio-diagnostic kits for estimation of tissue malondialdehyde (MDA) levels.

\section{3- Experimental animals}

This study was carried out on 40 adult male albino rats weighing (150-200 gm). They were obtained from the breeding animal house of Faculty of Veterinary Medicine, Zagazig University. Before commencing the experimentation, all animals were subjected to 14 days period of passive preliminaries in order to adapt themselves to their new environment. They were maintained on a standard diet, and water was available ad libitum. The experiment was performed in accordance with the "Guide for the Care and Use of Laboratory Animals" (Institute of Laboratory Animal Resources, 1996).

The rats were divided into four groups; each group consisted of 10 rats:
- Group 1 (Negative Control Group): Kept without treatment for 8 weeks.

- Group 2 (Positive Control Group): Received only the vehicle (each rat received $1 \mathrm{ml}$ of $1 \mathrm{~N} \mathrm{NaOH}$ added to $1000 \mathrm{ml}$ of tap water and given ad libitum as drinking water for 8 weeks).

- Group 3 (GA3 Group): Seventy five $\mathrm{mg}$ of GA3 were dissolved in $1 \mathrm{ml}$ of $1 \mathrm{~N} \mathrm{NaOH}$ and then were diluted with tap water until $1000 \mathrm{ml}$ to obtain a 75 ppm dose to be given ad libitum as drinking water to these animals for 8 weeks. This duration is accepted to be sub-chronic exposure as stated by Tuluce and Celic (2006). Since all rats have the same physiologic characters, daily water consumption of all rats was approximately $30 \pm$ $3 \mathrm{ml}$ during the test. Consequently, the GA3 intake amount of each rat was about $2.2 \pm 0.3 \mathrm{mg}$ per day which was the dose used in the study of Celik et al. (2007) to induce GA3induced testicular toxicity.

- Group 4 (Recovery Group): Animals of this group received the same treatment as group 3 for 8 weeks, and then they were left without any treatment for another 8 weeks. According to the study of Sally (1998), reversibility of GA3induced toxic changes was incomplete after stoppage of GA3 administration for another period equals to half of GA3-administartion period. Accordingly in the present study, reversibility was allowed for the same duration of GA3administration.

At the end of the specified durations ( 8 and 16 weeks), rats were anaesthetized by ether and sacrificed for epididymal spermatozoa examination and assessment of testicular malondialdhyde (MDA) level. Testicular specimens were collected to be subjected to histopathological examination using both light and electron microscopes.

\section{B- Methods}

\section{1- Methods used for epididymal spermatozoal examination}

Spermatozoa collection was done as described by Klinefelter et al. (1991). Epididymal content of each rat was obtained immediately by cutting the tail of epididymis and squeezing it gently to obtain the fresh undiluted semen in a clean Petri dish to perform the following examinations:

\section{a) Epididymal sperm viability}

A drop of Epididymal content of each rat was mixed with an equal drop of eosin-nigrosin stain. The 
semen was carefully mixed with the stain, then films from the mixtures were spread on clean and grease-free slides. Two hundred sperms were counted per rat under high power lens of light microscope and the number of live (unstained) and dead (stained) sperms were estimated among the two hundred sperms. Then the percentage of viability was calculated (Tardif et al., 1999).

\section{b) Sperm count}

Sperm cell concentration was estimated according to the method reported by Blazak et al. (1993). The pipette of hemocytometer was used. The undiluted semen was withdrawn up to the mark 0.1 and pipette was then filled up to the mark 101 by normal saline stained with eosin. Then the pipette content was shaken vigorously by holding the ends of the pipette between the thumb and the index. A cover slide was placed over the counting chamber and a drop of diluted semen was spread between the haemocytometer chambers and its cover. Then sperms in 5 large squares (80 small squares) were counted using high power of microscope $(40 \mathrm{x})$. The sperm cell concentration was estimated by multiplying the counted number of sperms by 100 (depth) and 1000 (dilution).

\section{2-Assessment of testicular tissue oxidative stress}

One testis was wrapped with aluminum foil and embedded in liquid nitrogen for 1 hour then kept frozen in $-80^{\circ} \mathrm{C}$ till used to assess MDA level. Assessment of MDA level was done as described by Satoh (1978) according to the pamphlet of Bio diagnostic kits using colorimetric method.

\section{3- Histopathological Examination}

\section{Light microscopic study}

Testis specimens were fixed in $10 \%$ formalin saline for histopathological examination using $\mathrm{H} \& \mathrm{E}$ stain by the method described by Wilson \& Gamble (2002).

\section{Electron microscopic study}

According to the method of Glauret \& Lewis (1998), testis specimens were fixed in $2 \%$ glutaraldehyde and then post fixed in 1\% osmium tetroxide, dehydrated and embedded in epoxy resin. The specimens were carried out by Leica Ultracut (UCT) with glass knives. 0.5- 1 um sections (semi-thin sections) were preliminary obtained and mounted on glass slides. Then ultrathin sections $(70-90 \mathrm{~nm}$ colored pale gold) were obtained from the selected blocks and mounted on copper grids. Ultrathin sections were cut and double stained with uranyle acetate and lead citrate, then examined by transmission electron microscope at electron microscope laboratory in Histology Department, Faculty of Medicine, Zagazig University.

\section{Immunohistochemical study}

Immunostaining was performed using the avidin-biotin peroxidase technique for localization of Bcl-2. Paraffin sections mounted on coated slides were deparaffinized and treated with $0.01 \mathrm{M}$ citrate buffer for 10 minutes to unmask antigens. Then sections were incubated in $\mathrm{H} 2 \mathrm{O} 2$ for 10 minutes to abolish endogenous peroxidase activity before blocking with $5 \%$ horse serum for $2 \mathrm{hrs}$ at room temperature to inhibit the nonspecific immunoreactions. Primary monoclonal anti- Bcl-2 serum (Cell Marque Lot., 27068) was applied at 1:5000 dilutions. Sections were incubated with primary monoclonal antisera for $36 \mathrm{~h}$ at 4oC. After washing they were incubated with biotinylated secondary antibodies for $5 \mathrm{hrs}$, then followed by avidin-biotin peroxidase complex. Finally immune reaction was visualized with $0.05 \%$ diaminobenzidine. Then the slides were counter stained with Mayer's hematoxylin before mounting (Happerfield et al., 1993).

\section{4- Statistical analysis}

For statistical analysis, SPSS 13.0 for windows programme was used. Data was represented as means \pm SD. The differences were compared for statistical significance by ANOVA. Statistical difference between groups was calculated by LSD. Difference was considered significant at $\mathrm{p}<0.05$.

\section{Results}

\section{1- Epididymal spermatozoal examination}

\section{1-1 Epididymal sperm viability (Figure-1a, b, c,} d):

In control groups (Figure-1a), normal spermatozoa appeared with hocked heads containing dense nucleus and apical light acrosome in eosinnigrosin stain. GA3 treatment caused the sperms to have bent necks and tails (Figure-1b, c). In recovery period, rats showed normal and abnormal (with flat head) sperms (Figure-1d).

\section{1-2 Sperm count (Table-1)}

Semen analysis results sperm count $(106 / \mathrm{mm} 3)$ and the percents $(\%)$ of sperm viability $\}$ of the control groups were within normal values and showed statistically insignificant $(p>0.05)$ changes through the study. Oral administration of GA3 to adult male albino rats for 8 weeks has resulted in a statistically significant decrease $(p<0.001)$ in the mean values of the sperm count and viability when compared with those of the control groups. In the recovery group, semen analysis results showed significant increases compared to GA3 treated group $(p<0.05)$, and significant decreases $(\mathrm{p}<0.05)$ compared to control groups.

\section{2- Assessment of oxidative stress by testicular malondialdhyde (MDA) level (Table-2)}

GA3 treatment induced a significant increase in the testicular level of MDA $(p<0.001)$ compared to the control groups. The 8 weeks period of recovery revealed significant improvement in the testicular MDA level when compared to those of GA3 treated group $(\mathrm{p}<0.01)$. This improvement was partial because these values were still significantly $(p<0.001)$ higher than those of the control groups. 


\section{3- Histopathological results}

\section{3-1 Light microscopic results}

\section{H\&E stain}

Examination of H\&E stained testis sections of the control groups showed seminiferous tubules surrounded by basal lamina and separated by interstitial connective tissue septa. They were lined by stratified germinal epithelium with spermatogonia adjacent to the basal lamina and abundant sperms in the lumen (Figure- 2a).

Testes sections of GA3 treated group revealed disappearance of spermatozoa in the lumen of many seminiferous tubules and reduction in all stages of spermatogenesis (Figure- 2b). Upon recovery, testicular sections revealed variable degrees of recovery. Some seminiferous tubules were still affected and the remaining ones showed normal appearance and even hyperactivity (Figure- 2c,d).

\section{Toluidine blue stain}

Examination of toluidine blue stained semithin sections of the control testes showed the seminiferous tubules surrounded by basal lamina. They were lined by spermatogonia located directly above the basal lamina with spherical or oval nuclei. The Sertoli cells with their lateral processes divided the tubule into basal compartment which contained spermatogonia and adluminal compartment contained primary spermatocytes which were the largest germ cells. Above the primary spermatocytes there were many layers of early spermatids which appeared smaller, lightly stained with rounded nuclei. Late spermatids appeared with darkly stained nuclei and darkly stained sperm heads in the lumen. The developing cells were connected to each other showing the clonal nature of the germ cells (Figure- 3a). Testes sections of GA3 treated group showed regression in the sequence of all stages of spermatogenesis. Also there was loss of clonal nature of germ cells in comparison to control group (Figure- 3b). Upon recovery, hyperactive seminiferous tubules were observed in testicular sections with increased spermatogenic cells and luminal sperms (Figure- 3c).

\section{3-2 Electron microscopic results}

Electron microscopic study of the control group showed the ultra structure of the testis. The seminiferous tubules lined by spermatogonia and Sertoli cells with their lateral processes divided the tubule into basal compartment and adluminal compartments. The latter contained different stages of spermatocytes (early and late spermatids). The spermatids were characterized by the presence of peripherally arranged tubular mitochondria and the nuclei of some cells showed the start of formation of acrosomal heads sperm heads and the cytoplasmic residual bodies were seen free in the lumen (Figure$4 a)$.

Sections of GA3 treated group revealed apoptosis of many spermatogonia. Sertoli cells showed reduction in the cytoplasmic processes with apoptotic nucleus (Figure- 4b). Distortion of the adluminal compartment with many apoptotic cells was also detected (Fig. 4c). In the recovery group, electron microscopic study of testes sections of this group showed the recovered seminiferous tubules impacted with clonal sequence of spermatogenic cells and the sperms reappeared in the lumen (Figure- 4d).

\section{3-3 Immunohistochemical results}

Examination of the testis sections stained by immunoperoxidase technique for demonstration of Bcl2 revealed strong cytoplasmic immunoreaction for Bcl2 in the layers of spermatids in the seminiferous tubules of the control group (Figure- 5a). Weak Bcl-2 immunoreaction was found in a few scattered spermatids in the affected seminiferous tubules of rats receiving GA3 orally for 8 weeks (group II) (Figure$5 b)$. Upon recovery (group III), the spermatids of the recovered tubules showed strong immunoreaction for Bcl-2 whereas the cells of the still affected tubules showed weak reaction (Figure- $5 \mathrm{c}$ ).

Table-1: Statistical analysis by ANOVA and LSD of mean values of semen analysis results of negative control rats (groups 1), positive control rats (groups 2), GA3 treated rats (group 3) and recovery group (group 4), 10 rats/group.

\begin{tabular}{|c|c|c|c|c|c|}
\hline \multicolumn{2}{|c|}{ Parameter } & Group 1 & Group 2 & Group 3 & Group 4 \\
\hline \multirow{2}{*}{$\begin{array}{c}\text { Epididymal spermatozoal } \\
\text { examination }\end{array}$} & $\begin{array}{l}\text { Sperm count } \\
\left(10^{6} / \mathrm{mm}^{3}\right)\end{array}$ & $83.50 \pm 8.29$ & $82.25 \pm 7.99$ & $10.19 \pm 2.64^{\mathrm{a}}$ & $57.40 \pm 3.14^{\mathrm{b}, \mathrm{c}}$ \\
\hline & $\begin{array}{l}\text { Epididymal sperm } \\
\text { viability percent }\end{array}$ & $90.10 \pm 2.72 \%$ & $92.30 \pm 2.20 \%$ & $18.68 \pm 4.44 \%{ }^{\mathrm{a}}$ & $50.75 \pm 15.75 \%{ }^{b, c}$ \\
\hline
\end{tabular}

Data are expressed in terms of mean and standard deviation $(X+S D)$

a: significant decrease compared to control groups at $p<0.001$

b: significant decrease compared to control groups at $p<0.05$

c: significant increase compared to GA3 treated group at $p<0.05$

Table 2: Statistical analysis by ANOVA and LSD of mean values of malondialdhyde (MDA) results in $\mathrm{nmol} / \mathrm{mg}$ protein of negative control rats (groups 1), positive control rats (groups 2), GA3 treated rats (Group 3) and recovery group (group 4), 10 rats/group.

\begin{tabular}{|c|c|c|c|c|}
\hline Parameter & Group 1 & Group 2 & Group 3 & Group 4 \\
\hline Testicular MDA (nmol/mg protein) & $144.2 \pm 11.5$ & $129.7 \pm 1.1$ & $323.4 \pm 32.4^{\mathrm{a}}$ & $227.8 \pm 19.5^{\mathrm{a}, \mathrm{b}}$ \\
\hline
\end{tabular}

Data are expressed in terms of mean and standard deviation $(X \pm S D)$

a: significant increase compared to control groups at $p \leq 0.001$

b: significant decrease compared to GA3 treated group at $p \leq 0.01$ 


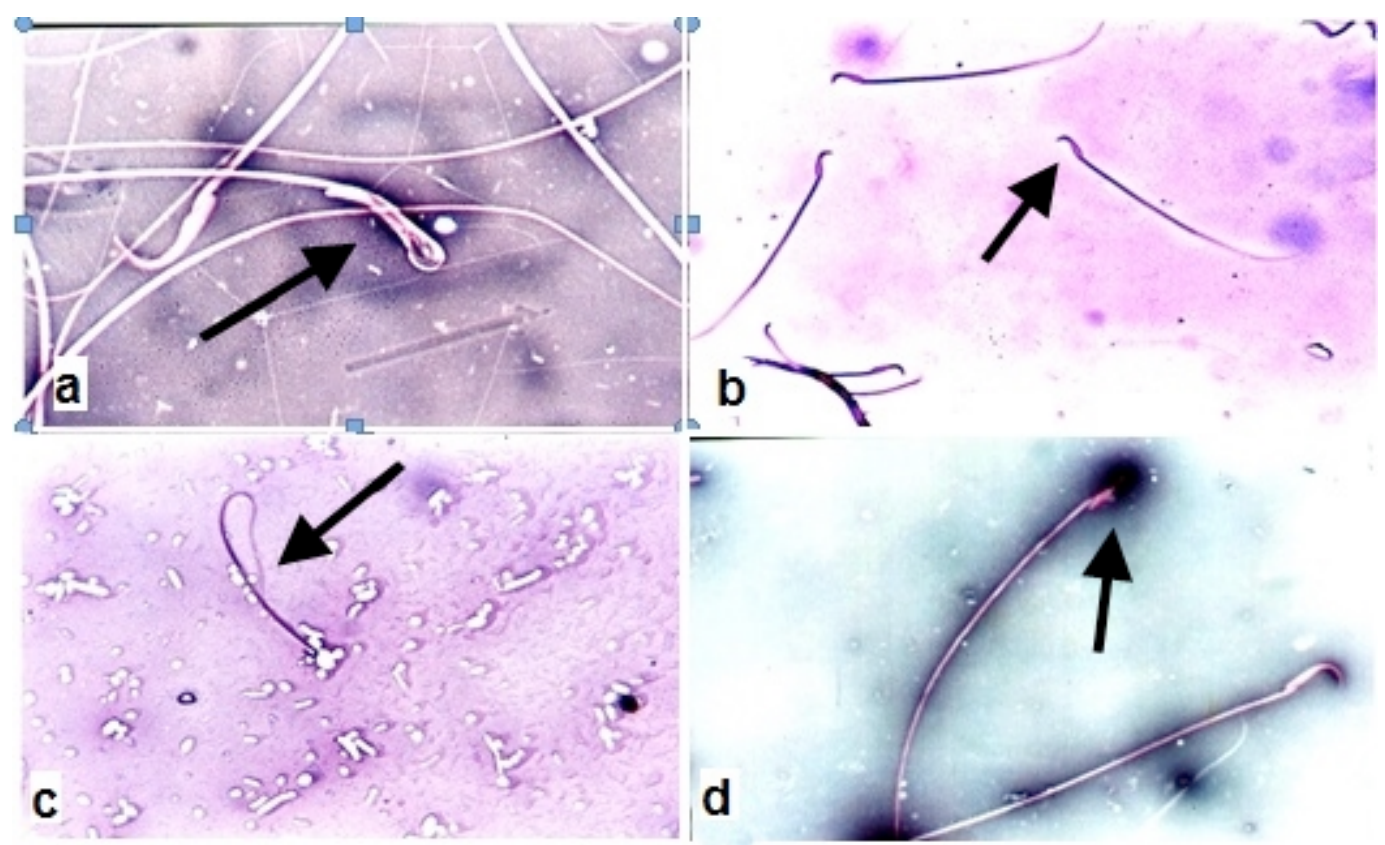

Figure-1: A photomicrograph of epididymal spermatozoa from adult male albino rats (a) control group showing normal spermatozoa with hocked heads containing dense nucleus and apical light acrosome (arrow), (b\&c) group receiving GA3 orally for 8 weeks showing sperms with bent necks and tails (arrow), (d) group receiving GA3 orally for 8 weeks then allowed to recover for 8 weeks showing normal and abnormal (flat head) sperms (Eosin-nigrosin stain X400).
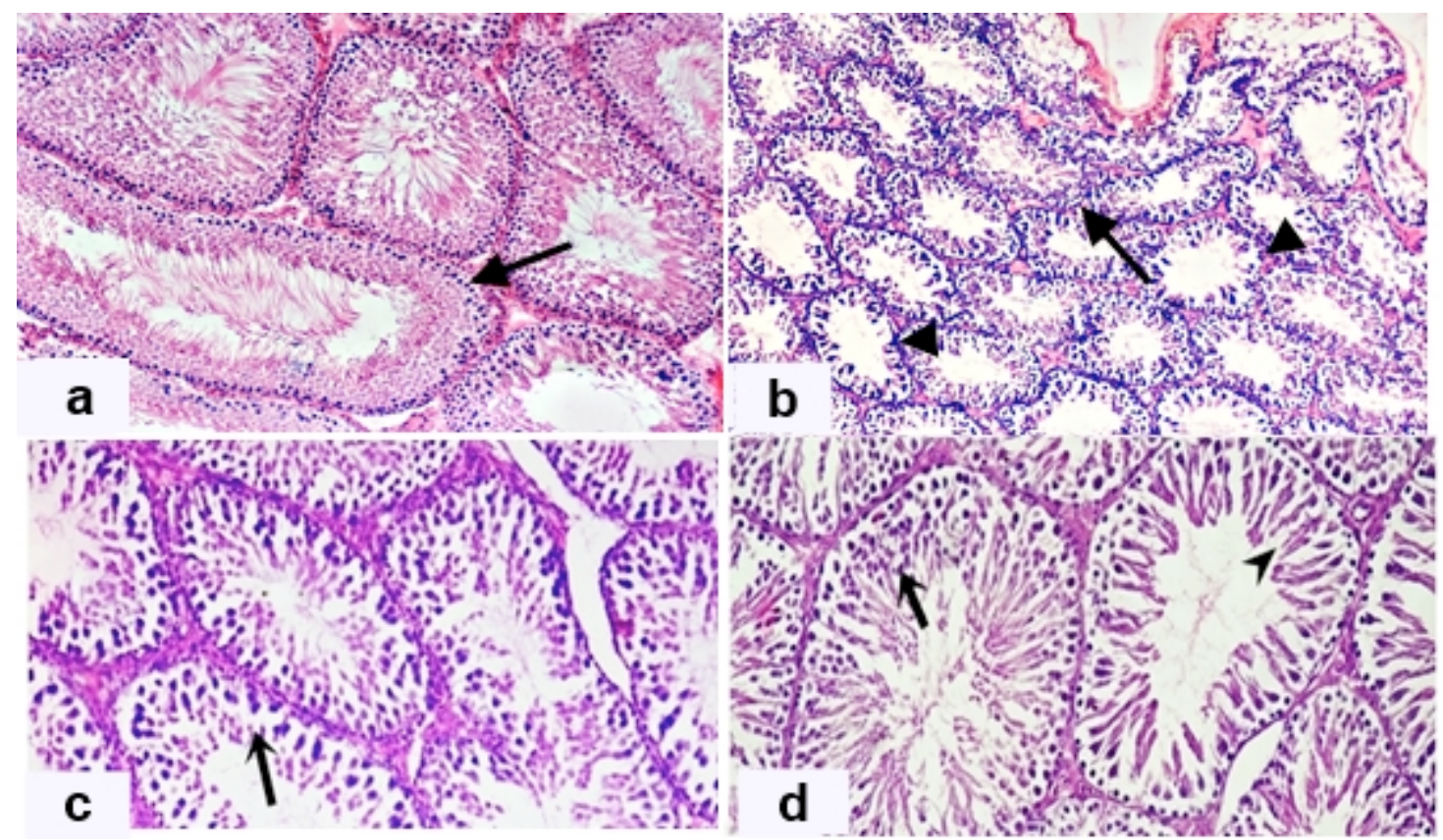

Figure-2: A photomicrograph of a section in the testes obtained from an adult male albino rat (a) control group showing many seminiferous tubules lined with germinal seminiferous epithelium and the sperms in the lumen (arrow), (b) group receiving GA3 orally for 8 weeks showing many seminiferous tubules with hypospermatogenesis and wide lumens (arrow head) containing few spermatozoa (arrow), (c) group receiving GA3 orally for 8 weeks then allowed to recover for 8 weeks showing affected seminiferous tubule (arrow), (d) group receiving GA3 orally for 8 weeks then allowed to recover for 8 weeks showing normal appearance of another one (arrow head). The third tubule appears hypercellular (arrow) (H\&E stain X200). 


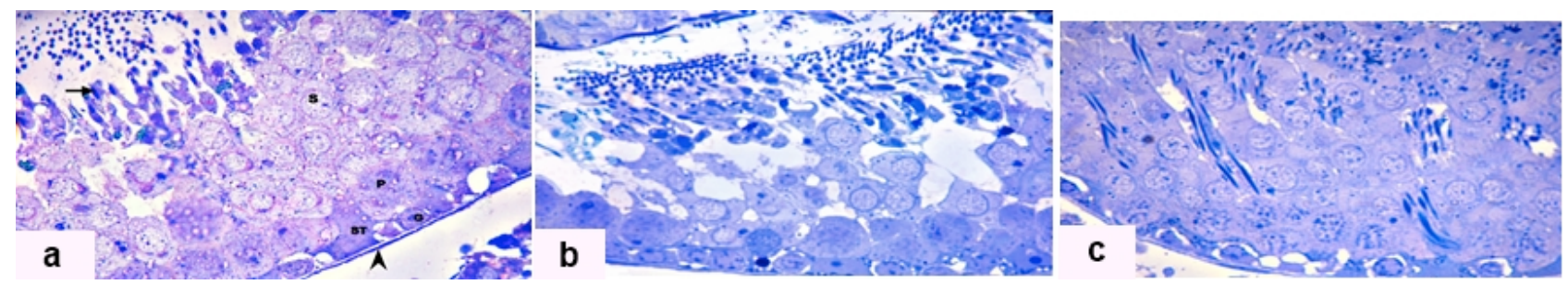

Figure-3: A photomicrograph of a section in the testes obtained from an adult male albino rat (a) control group showing part of the seminiferous tubule surrounded by basal lamina (arrow head). The seminiferous tubule is lined by spermatogonia (G) and Sertoli cell (ST). The next layers show primary spermatocytes (P), spermatids (S) with rounded nuclei, and darkly stained sperm heads (arrow) in the lumen. The developing cells are connected to each other showing the clonal nature of the germ cells, (b) group receiving GA3 orally for 8 weeks showing part of a seminiferous tubule surrounded by basal lamina with regression in the sequence of all stages of spermatogenesis. There is loss of clonal nature of germ cells compared to the control group, (c) group receiving GA3 orally for 8 weeks then allowed to recover for 8 weeks showing hyperactivity of seminiferous tubules in the form of increased layers of regenerated spermatogenic cells (Toluidine blue X1000)

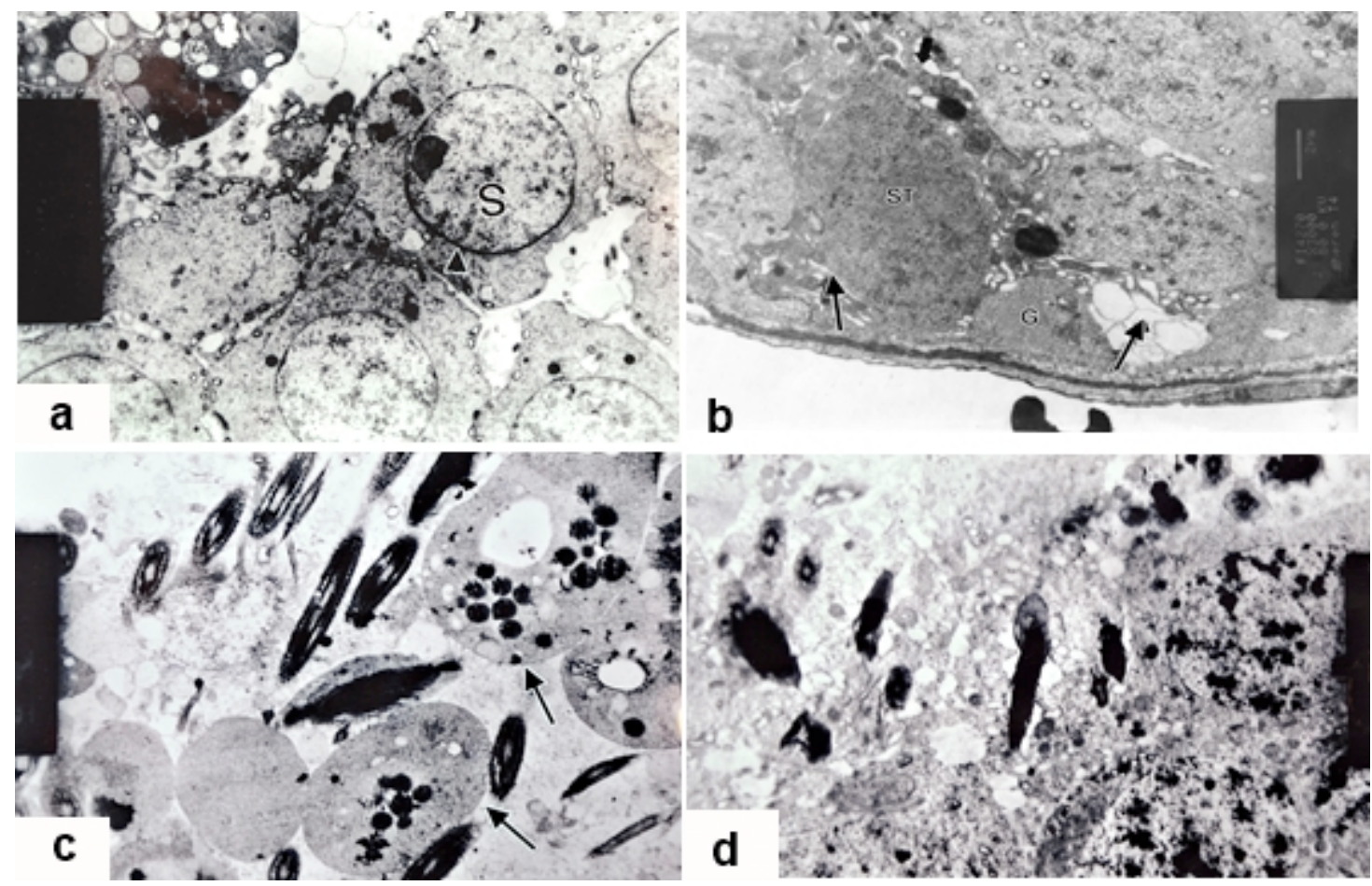

Figure-4: An electron micrograph of a section in the testes obtained from an adult male albino rat (a) control group showing part the adluminal compartment with spermatids (S) containing peripherally arranged tubular mitochondria and the nuclei of some cells show the start of formation of acrosomal heads (arrow heads). Notice residual bodies in the lumen, (b) group receiving GA3 orally for 8 weeks showing apoptotic changes in both spermatogonia (G) and Sertoli cell (ST). They appear electron dense and vacuolated (arrow) with homogenization in the content of the cytoplasm. The Sertoli cell shows reduction in the cytoplasmic processes, (c) group receiving GA3 orally for 8 weeks showing distortion of the adluminal compartment with many apoptotic cells (arrows), (d) group orally receiving GA3 orally for 8 weeks then allowed to recover for 8 weeks showing part of a seminiferous tubule impacted with apparently normal spermatids and the sperms reappeared in the lumen (X4000). 


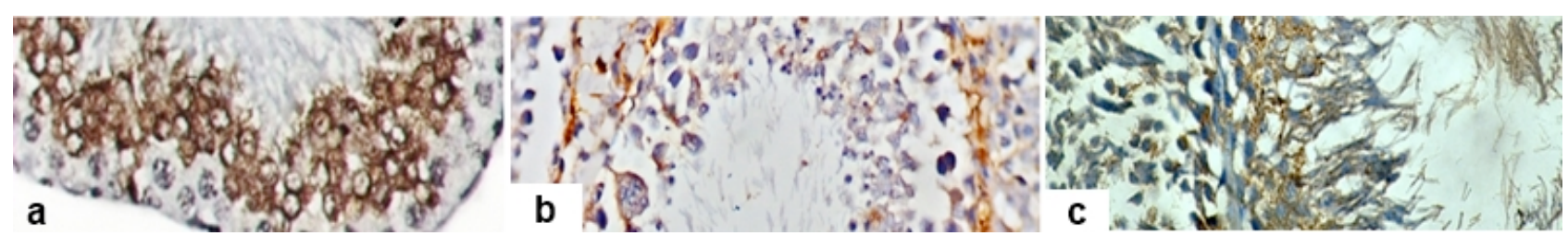

Figure-5: A photomicrograph of a section in the testes obtained from adult male albino rats stained by immunoperoxidase technique for demonstration of Bcl-2. (a) control group showing strong cytoplasmic immunoreaction for Bcl-2 in the layers of spermatids, (b) group receiving GA3 orally for 8 weeks showing week Bcl-2 immunoreaction in few spermatids, (c) group receiving GA3 orally for 8 weeks then allowed to recover for 8 weeks showing parts of two adjacent seminiferous tubules, the spermatids of the right one show strong immunoreaction for Bcl-2 whereas the cells of the left tubule show week reaction (X400).

\section{Discussion}

In the present study, oral administration of GA3 for 8 weeks (sub-chronic exposure) resulted in significant increase in testicular malondialdehyde with significant decreases in sperm count and epididymal sperm viability. These changes were supported by the histopathological changes under light and electron microscopic examination.

The obtained elevation in testicular MDA due to GA3 administration recorded in the present study can be explained by the study of Soliman et al. (2010) who stated that PGRs are associated with the generation of reactive oxygen species which interact with tissues leading to numerous pathophysiological alterations. These reactive oxygen species could damage every major cellular component, including membranes, lipids, carbohydrates and DNA (Bhalla \& Dhawan, 2009; Chen et al. 2012). Therefore, GA3 treatment might cause peroxidation of polyunsaturated fatty acids leading to severe functional disorder of sperm (Sanocka \& Kurpisz, 2004), morphological defects (Ates et al., 2004) and cellular deterioration (Troudi et al., 2011). Testicular MDA elevation coincides with the study of Muthuraman \& Srikumar (2009) who stated that rats treated with GA3 showed a significant increase in testicular level of MDA compared to control group.

The histopathological finding in the present study coincided with Skinner (1991) who found out that GA3 administration to experimental rats affected the Leydig cells negatively, resulting in the degeneration and maturation arrest of germ cells. Later on, similar results were obtained by Lohiya et al. (2002) who stated that derangement of germ cells secondary to dystrophied Leydig cells made GA3 a potent endocrine disruptor in rat testicular cells.

Also, these abnormal findings were in agreement with Ravikumar \& Srikumar (2005) who stated that GA3 had a dysregulatory role in rats' testicular cell functions and might serve as an inhibitor of testicular cell function. They described the histological findings to be in the form of loss of germ cells, loss of the clonal arrangement of the germinal epithelial cells in the seminiferous tubules, decreased sperm count in the lumen, reduction in the size of the seminiferous tubules and dystrophy of Leydig cells. In addition to the histological finding, they reported a gradual decrease in total protein content of testicular cells.
Recently, the data presented in the study of Hassan et al. (2013) showed that GA3 caused significant inreases in testicular lipid peroxidation product (MDA) and hydrogen peroxide (H2O2) levels. Moreover, there was a number of histopathological testicular changes including Leydig's cell degeneration, reduction in seminiferous tubule with necrotic symptoms and sperm degeneration in GA3treated rats.

To explain the defective spermatogenesis in the present study, Scanlon \& Sanders (2005) and Steven \& Lowe (2006) stated that Sertoli cell's overall shape is somewhat Christmas-tree-shaped. The apical and lateral plasma membranes have irregular "pockets" which house the developing sperms and give them the clonal arrangements in the seminiferous tubules. The early stage cells in the line of sperm development are located near the base of the "trunk", and as they develop into later stages, the spermatocytes are moved up into the "branches" of the tree. So reductions in the cytoplasmic processes of Sertoli cells as evidenced in this study might affect the clonal arrangement of the germinal epithelial cells in the seminiferous tubules.

Later on, Kumar \& Muralidhara (2007) stated that Sertoli cells protect the developing sperm cells by formation of the blood-testis barrier which separates the seminiferous tubules into two compartments (basal compartment and adluminal compartment). The developing sperms are sequestered in the adluminal compartment that is isolated from the serum or lymph. As a result of this, the Sertoli cells supply the developing sperms with adequate requirements. Affection of Sertoli cells might lead to deprivation of the adluminal compartment from requirements necessary for their development and completion of spermatogenesis.

Another postulation has been proposed by Vikramathithan et al. (2009) who mentioned that Lactate dehydrogenase (LDH) enzyme activity decreased in the testes of rats treated with GA3. Inhibition of $\mathrm{LDH}$ prevented lactic acid accumulation in tissues (Lactic acid is one of the compounds that is produced by the Sertoli cells and utilized primarily by the germ cells for ATP production as mentioned by Erkkila et al. (2002). So, the affected Sertoli cell might decrease the testicular level of LDH enzyme and subsequent decreased lactic acid production with arrest of spermatogenesis. 
The Bcl-2 gene family members, as stated by Tsujimoto \& Shimizu (2000), have been shown to hold key genetic elements in modulating apoptosis by means of regulating mitochondrial-dependent programmed cell death. In the current study, the anti-apoptotic protein Bcl-2 showed weak immunoreaction in few scattered spermatids in the affected seminiferous tubules of GA3-treated rats denoting increased cellular apoptosis.

Apoptosis is often markedly increased after exposure to a testicular toxicant which indicates that the seminiferous epithelium is dysfunctional and cannot provide optimal support either due to affection of Sertoli cells, Leydig cells or due to direct severe damage to germ cells (Boekelheide, 2005). Accordingly, the weak Bcl-2 immunoreaction which occurred in the testes of GA3 treated rats can be explained by the study of Xie et al. (2009) who found that GA3-driven apoptotic events were associated with up-regulation of Bax (Proapoptotic protein) and downregulation of Bcl-2 (Antiapoptotic protein). Moreover, GA3 triggered cytochrome-c release from the mitochondria, in particular, bypassing the involvement of the mitochondrial membrane potential.

In the present study, after 8-weeks of withholding GA3 administration (follow up group), significant improvement in testicular MDA, testicular function and structure with improvement of $\mathrm{Bcl}-2$ immunoreaction was detected. To our knowledge, no available data exists regarding the explanation of the improvement in testicular structure and function upon withholding GA3 administration.

In an attempt to explain this improvement which occurred in the follow up group after withholding GA3 administration for 8 weeks, Alvarez \& Storey (1989) stated that lipid peroxidation increases significantly either through the inhibition of glutathione peroxidase (GPX) or by depleting glutathione (GSH) availability. Most available data indicates that GA3 causes its detrimental effects through generation of reactive oxygen species (ROS). Accordingly in the current study, lipid peroxidation most probably occurred due to GSH over use and hence depletion and not through inhibition of glutathione peroxidase (GPX). This is supported by the findings of the study of Hassan et al. (2013) who found out that GA3 caused significant decreases in the total antioxidant capacity, glutathione, sulphahydryl group content, as well as superoxide dismutase, catalase, and glucose-6-phosphate dehydrogenase activity.

Accordingly, the 8-weeks period of GA3 withholding (recovery period) allowed for repletion of testicular GSH, with further improvement of spermatogenesis. This can be explained by the study of Nolte et al. (1995) who stated in their review that rats exposed to chemically-induced testicular atrophy show regeneration and repopulation of sperms by the second month, and resulting in the production of an appreciable number of sperm within 8 weeks after stoppage of exposure. They added that testicular toxicities caused by substances which act on spermatocytes, spermatids and spermatozoa are completely reversible. Also, Creasy \& Foster (1991) stated that in a 13 -weeks toxicity study with a 42 days post exposure period, a strong tendency towards repopulation was present, but it was still incomplete in a number of animals.

Reversibility of GA3-induced testicular pathological changes has been recorded in a former study after the administration of Proanthocyanidin (PAC), a natural and safe compound that has beneficial effects on health, which caused significant histopathological improvement in testicular tissues (Jiao et al. 2005). This result was related to the reduction of lipid peroxidation through scavenging ROS by the antioxidative activity of PAC.

\section{Conclusion}

The observations presented in this work led us to conclude that gibberellic acid (GA3) can induce testicular pathological changes, a decrease in sperm count and epididymal sperm viability on administration for 8-weeks via the oral route. These changes are most probably due to lipid peroxidation. Although, withholding of GA3 administration for a further 8 weeks, didn't cause complete testicular recovery; it signifies that GA3-induced testicular toxicity is reversible. Further studies should be directed to detect other possible GA3-induced toxicities. Moreover, the use of natural antioxidants, for their ameliorative effect against GA3-induced testicular toxicity, should be studied.

\section{Acknowledgment}

The authors wish to acknowledge the role of the Postgraduate Research Studies Section in Zagazig University for complete funding of this project through the Research Project Management Unit, Zagazig University, Egypt, as well as Prof. Wafaa F. Hussein, project manager, for her valuable support.

\section{References}

Alvarez JG and Storey BT (1989): Role of glutathione peroxidase in protecting mammalian spermatozoa from loss of motility caused by spontaneous lipid peroxidation. Gamete Res. 23: 77-90.

Ates I, Suzen HS, Aydin A et al., (2004): The oxidative DNA base damage in testes of rats after intraperitoneal cadmium injection. Biometals.17(4):371-7.

Bhalla P and Dhawan DK (2009): Protective role of lithium in ameliorating the aluminium induced oxidative stress and histological changes in rat brain. Cell Mol Neurobiol. 29:513-21.

Blazak WF, Treinen KA and Juniewicz PE (1993): Application of Testicular Sperm Head Counts in the Assessment of Male Reproductive Toxicity. In: Methods in Toxicology, Vol. 3, Part A, Male Reproductive Toxicology. Chapin R. E. and Heindel J. J. (eds). Academic Press, Inc., San Diego, pp. 86-94. 
Boekelheide K (2005): Mechanisms of Toxic Damage to Spermatogenesis. JNCI Monographs. 34:68.

Celik I and Tuluce Y (2006): Effects of indoleacetic acid and kinetin on lipid peroxidation and antioxidant defense in various tissues of rats. Pesticide Biochemistry and Physiology. 84: 49-54.

Celik I, Turker M and Tuluce Y (2007): Abcisic acid and gibberellic acid cause increased lipid peroxidation and fluctuated antioxidant defense systems of various tissues in rats. $\mathrm{J}$ Hazardous Materials. 148: 623-9.

Chen Z, Jiang H, Wan Y, Bi C et al., (2012). H2O2induced secretion of tumor necrosis factor-a evokes apoptosis of cardiac myocytes through reactive oxygen species-dependent activation of p38 MAPK. Cytotecnology. 64:65-73.

Creasy DM and Foster PM (1991): Male reproductive system. In: HASCHEK WM, ROUSSEAUX CG (eds) Handbook of toxicologic pathology. Academic Press; San Diego, pp 829-89.

Drira N (2006): In vitro vegetative growth and flowering of olive tree in response to GA3 treatment. Afr.J.Biotech.. 5(22):2097-302.

Erkkilä KH, Aalto AK, Pentikäinen V et al., (2002): Lactate inhibits germ cell apoptosis in the human testis. Molecular Human Reproduction, European Society of Human Reproduction and Embryology. 8(2): 109-17.

Fishel FM (2006): Gibberellins. Agronomy department, Florida cooperative extension service, Institute of food and agricultural sciences, University of Florida, USA. http://edis.ifas.ufl.edu.I

Glauret A and Lewis P (1998): Physiologic specimen preparation for transmission Electron Microscope1 ed., vol. 17., Portland Press, London.

Happerfield LC, Bobrow LG, Bains RM et al., (1993): Peroxidase labeling immunocytochemistry: a comparison of eleven commercially available avidin-biotin systems. J Histochem Cytochem. 41: 291-302.

Hassan HA, Isa AM, El-Kholy WM et al., (2013): Testicular disorders induced by plant growth regulators: cellular protection with proanthocyanidins grape seeds extract. Cytotechnology. 2013 Jan 6. [Epub ahead of print].

Institute of Laboratory Animal Resources, Commission on Life Sciences, National Research Council (1996): Guide for the Care and Use of Laboratory Animals. National Academy Press, Washington, D.C, pp.21-55, http://www.nap.edu/openbook.php

Jiao Z, Liu J and Wang S (2005): Antioxidant activities of total pigment extract from blackberries. Food Technol Biotechnol. 43:97-102.

Klinefelter GR, Gray LE and Suare JD (1991): The method of sperm collection significantly influences sperm motion parameters following ethane dimethanesulphonate administration in the rat. Reprod. Toxicol. 5: 39-44.

Kumar TR and Muralidhara A (2007): Induction of Oxidative Stress by Organic Hydroperoxides in Testis and Epididymal Sperm of Rats In Vivo. Journal of Andrology. 28(1):77-85.

Lohiya NK, Manivanna B, Mishara PK et al., (2002): Chloroform extract of Carica papaya seeds induces long term reversible azospermia in langur monkey. Asian Androl. 4(1):17- 26.

Muthuraman P and Srikumar K (2009): A comparative effect of homobrassinolide and gibberllic acid on lipid peroxidation and antioxidant defense in Alloxan induced diabetic male albino rats. Enzyme Inhibition and Medicinal Chemistry. 24:1122-7.

Nolte T, Harleman JH and Jahn W (1995): Histopathology of chemically induced testicular atrophy in rats. Exp Toxic Pathol. 47: 267-86.

Ravikumar S and Srikumar K (2005): Metabolic dysregulation and inhibition of spermatogenesis by gibberellic acid in rat testis. J Environ Biol. 26: 567-9.

Sally YA (1998): Chronic administration of plant growth hormones in rats; some histologic studies. Env Ass Un. 6:21-9.

Sanocka D and Kurpisz M (2004): Reactive oxygen species and sperm cells. Reprod Biol Endocrinol. 2:1-7.

Satoh K (1978): Serum lipid peroxide in cerebrovascular disorders determined by a new colorimetric method. Clin Chim Acta. 90: $37-43$.

Scanlon VC and Sanders T (2005): Testes In: Essentials of Anatomy and Physilolgy. 5th ed. Philadelphia; F.A. Davis Company. 550-83.

Schwechheimer C and Willige BC (2009): Shedding light on gibberellic acid signaling. Curr Opin Plant Biol. 12: 57-62.

Skinner MK (1991): Cell-Cell interaction in the testis. Endocr Rev. 12: 45-77.

Soliman HA, Mantawy MM and Hassan HM (2010): Biochemical and molecular profiles of gibberellic acid exposed albino rats. J Am Sci. 6:224-9.

Srikumar K, Vikramathithan J, Gautami G et al., (2009): Differences in rat tissue lactate dehydrogenase activity caused by giberellic acid and homobrassinolide. Turk J Biochem. 34:57-61.

Steven A and Lowe JS (2006): Testis. In: Human Histology, $3^{\text {rd }}$ ed., St Louis: Elsevier Mosby Ch., 23, pp875- 84 .

Tardif S, Laforest JP, Comier N et al., (1999): The importance of porcine sperm parameters on fertility in vivo. Theriogenology.52:447-59.

Troudi A, Ben Amara I, Soudani N, et al., (2011): Oxidative stress induced by gibberellic acid on kidney tissue of female rats and their progeny: biochemical and histopathological studies. J Phys Biochem. 67:307-16. 
Troudi A, Mahjoubi SA and Zeghal N (2010): Hepatotoxicity induced by gibberellic acid in adult rats and their progeny. Exp Toxicol Pathol. 18 (1): 127-33.

Tsujimoto Y and Shimizu S (2000): Bcl-2 family: lifeor-death switch. FEBS Lett. 466:6-10.

Tuluce Y and Celik I (2006): Influence of subacute and subchronic treatment of abcisic acid and gibberellic acid on serum marker enzymes and erythrocyte and tissue antioxidant defense systems and lipid peroxidation in rats. Pest Biochem Physiol. 86:85-92.

Vikramathitha J, Gautami G, Ganesh Iet al., (2009): Differences in Rat Tissue Lactate
Dehydrogenase Activity Caused by Giberellic Acid and Homobrassinolid Türk Biyokimya Dergisi [Turkish Journal of BiochemistryTurk J Biochem].34 (2): 57-61.

Wilson I and Gamble M (2002): The hematoxylins and eosins, In: Theory and practice of histological techniques, Bancroft JD and Gamble M (eds.), 5th ed., Churchill Livingston, Elservier Science Limited, London, UK, pp. 125-38.

Xie H, Qin Y, Zhou Y et al., (2009): GA3, a new gambogic acid derivative, exhibits potent antitumor activities in vitro via apoptosisinvolved mechanisms. Acta Pharmacologica Sinica. 30(3): 346.

\section{الملخص العربي}

\section{آثار التعرض المتكرر لحمض الجبريليك لقترة قصيرة المدي على خصية الجرذان البيضاء البالغة (دراسة كيمياء حيوية، ونسيجية، وهستوكيميائية مناعية)}

فاطمة يوسف فرحات و نرمين عطية عبد المنعم ابراهيم و شيرين أحمد الخطيب11 و عزة سعد شحاتة2

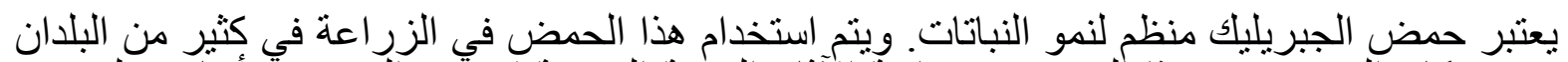

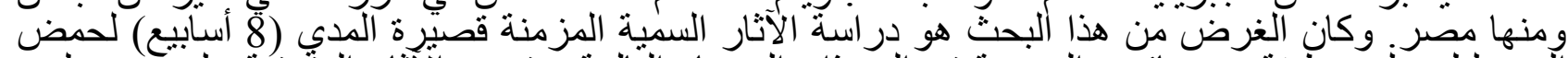

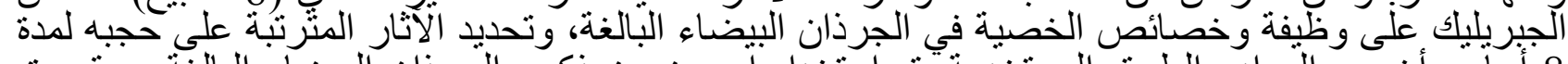

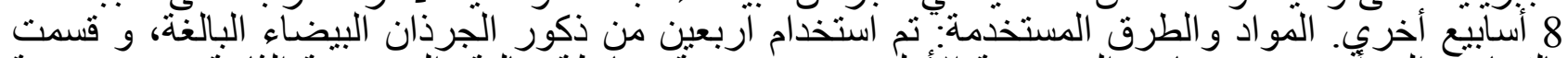

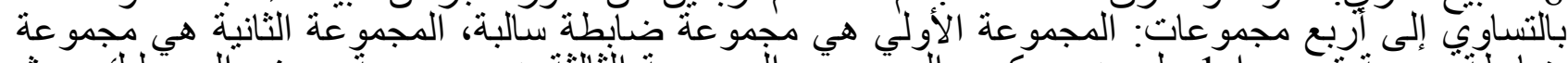

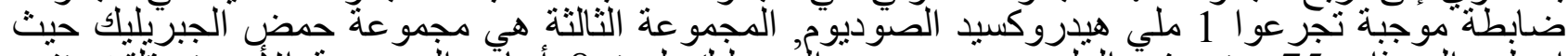

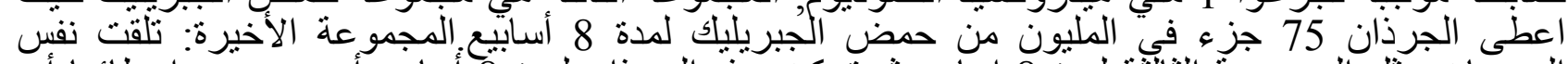

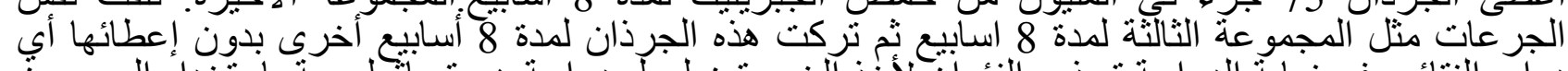

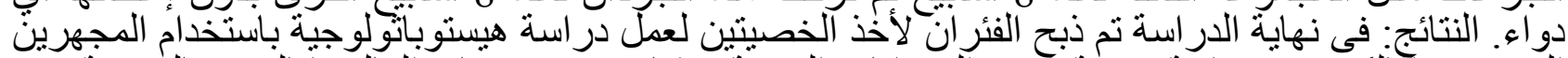

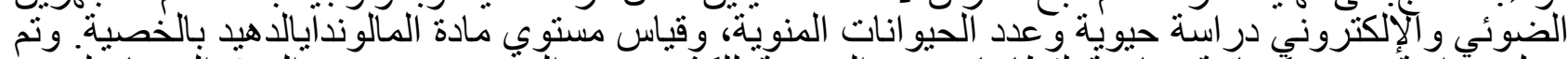

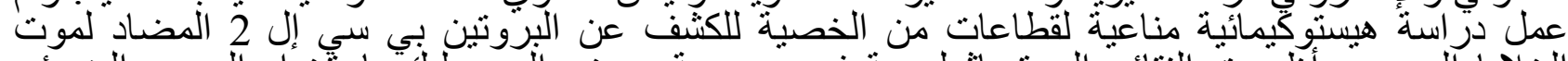

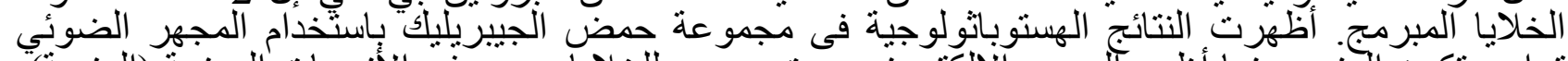

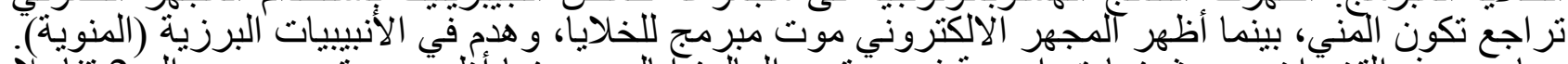

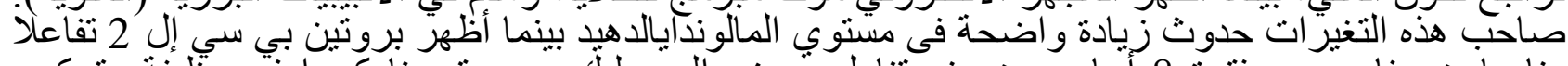

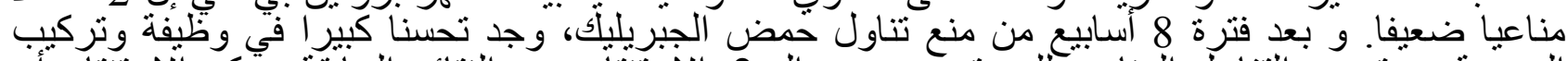

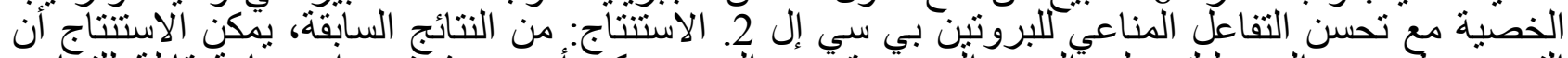

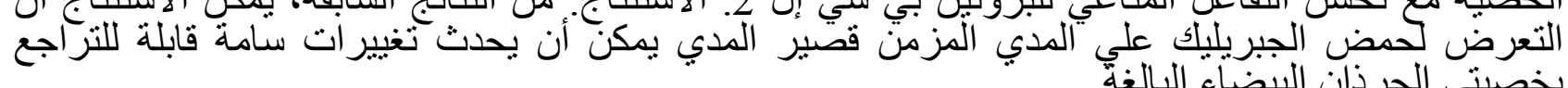

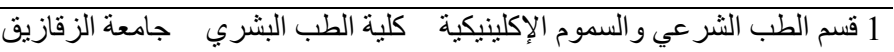

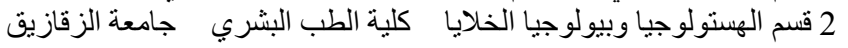

